\title{
INTEGRAÇÃO DE DADOS GPR E ERT NO ESTUDO DE CARBONATOS DA BACIA DE
} ITABORAÍ-RJ/BRASIL

\author{
MACHADO, L. V. T1', DIAS, G. A. N. ${ }^{1}$, BRAGA, M. A. ${ }^{1}$, Universidade Federal do Rio de Janeiro, Instituto de \\ Geociências, Departamento de Geologia, Av. Athos da Silveira Ramos, 274 - Bloco J1. Cidade Universitária,
}

Ilha do Fundão, 21941-916, Rio de Janeiro, RJ, Brasil

\section{Resumo}

Os métodos geofísicos Radar de Penetração no Solo (GPR) e Tomografia por Resistividade Elétrica ou Eletrorresistividade (ERT) foram integrados a fim de serem verificados a respostas desses aos carbonatos no Parque paleontológico de São José do Itaboraí - RJ. Todos os perfis foram obtidos próximos ao poço ao poço 2-ITAB-1-RJ na borda oeste da bacia. O método GPR foi utilizado a fim de ser observada a resposta quanto à propagação das ondas eletromagnéticas de altas frequências nesse meio e reconhecer a estruturas geológicas em profundidade, foram utilizados na aquisição o equipamento TerraSIRch SIR-3000 com antenas de $35 \mathrm{MHz}$ e $200 \mathrm{MHz}$. Os perfis do GPR com $18 \mathrm{~m}\left(\mathrm{~S} 10 \mathrm{~W}\left(170^{\circ}\right)\right), 34 \mathrm{~m}\left(\mathrm{~S} 45 \mathrm{~W}\left(225^{\circ}\right)\right)$ e $120 \mathrm{~m}$ $\left(\mathrm{N}\left(005^{\circ}\right)\right)$ de extensão onde foram processadas para remoção de ruídos e interpretadas no programa ReflexW. A utilização do outro método ERT procurou determinar a existência de corpos minerais e reconhecer estruturas geológicas, o equipamento de aquisição de dados utilizado em campo foi o Syscal Kid Switch-24 da IRIS Instruments com espaçamento de $5 \mathrm{~m}$, contendo 9 níveis de investigação e utilizando 24 eletrodos, com o arranjo dipolo-dipolo. Foram obtidas 03 linhas de aquisições de

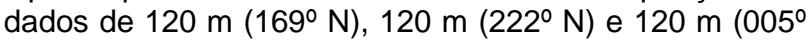
$\mathrm{N})$ de extensão, sendo os dados processados no software RES2DINV, para gerar as seções de resistividade. $O$ estudo apresentou relativa correlação entre as seções radargramas geradas pelas duas antenas com o perfil descrito do poço 2-ITAB-1-RJ. Pode se concluir que em estudos em carbonatos com algumas interfaces que variam com presença de carbonato, areia e aterro, verificados em seções estratigráficas podem ser ou não diferenciadas pelos métodos geofísicos utilizados nesse trabalho.

\section{Introdução}

A Bacia de São José de Itaboraí, ou simplesmente Bacia de Itaboraí, é a menor Bacia componente do Rift Continental do Sudeste do Brasil (RCSB), e considerada o primeiro segmento deste a se abrir, durante 0 Paleoceno. É a única Bacia do Rift que apresenta preenchimento carbonático expressivo e foi explorada por mais de 50 anos para produção de cimento.

A bacia é uma depressão elíptica fechada encravada em rochas do embasamento cristalino medindo $1400 \mathrm{~m}$ na direção $\mathrm{E}-\mathrm{W}$, eixo maior, e $700 \mathrm{~m}$, no eixo menor, de direção N-S, limitada ao sul pela falha de são José.
Este estudo procura contribuir na compreensão do método geofísico do Radar de Penetração de Solo (GPR) e eletrorresistividade (ERT) em rochas carbonáticas na Bacia de Itaboraí no município de Itaboraí, na Região Metropolitana da cidade do Rio de Janeiro - Brasil (Figura 1). O GPR é usado extensivamente para estudos de subsuperfície rasa, as ondas eletromagnéticas podem ser usadas para estudar materiais de diferentes permissividades dielétricas com baixa condutividade. A capacidade do GPR para mapear unidades de carbonato é relevante, pois consegue obter dados do relevo que se formam através da dissolução e recristalização de carbonato de cálcio em superfícies expostas e de superfícies de descontinuidades (SEIXAS, 2018). O ERT consiste na injeção de corrente elétrica na subsuperfície e de medida de diferença de potencial elétrico, resultante da interação da corrente com o meio, obtendo-se assim a resistividade. Os resultados das primeiras aplicações mostraram que a ERT pode fornecer um modelo geológico predito confiável, especialmente no caso de modelos geológicos complexos, onde os modelos geológicos de terrenos carbonáticos certamente pertencem.



Figura 1 - Mapa de localização da bacia de São José de Itaboraí, no Estado do Rio de Janeiro, Brasil, 2015. Fonte: adaptação autor.

\section{Geologia Regional}

O Sítio Paleontológico de Itaboraí situado no bairro São José, distrito de Cabuçu, Município de Itaboraí, na Região Metropolitana da cidade do Rio de Janeiro. As coordenadas geográficas do centro da área são $22^{\circ} 50^{\prime} 20^{\prime \prime} \mathrm{S}$ e $42^{\circ} 52^{\prime} 30^{\prime \prime} \mathrm{W}$. A bacia está localizada entre o maciço de Niterói, ao sul e, pela Serra dos Órgãos, ao norte ocupando uma pequena parte do vale de 
afundamento Campo Grande, Baía de Guanabara e Rio Bonito.

A bacia de São José de Itaboraí está inserida no contexto Rift Continental do Sudeste do Brasil (RCSB; RICCOMINI, 1989) (figura 2), que consiste em uma feição morfotectônica de idade paleogênica deprimida e alongada segundo ENE, com aproximadamente $900 \mathrm{~km}$ de comprimento, desenvolvida entre as cidades de Tijucas do Sul, no estado do Paraná, e a área submersa defronte a Macaé, no estado do Rio de Janeiro (RICCOMINI et al., 2004 apud ADLER).

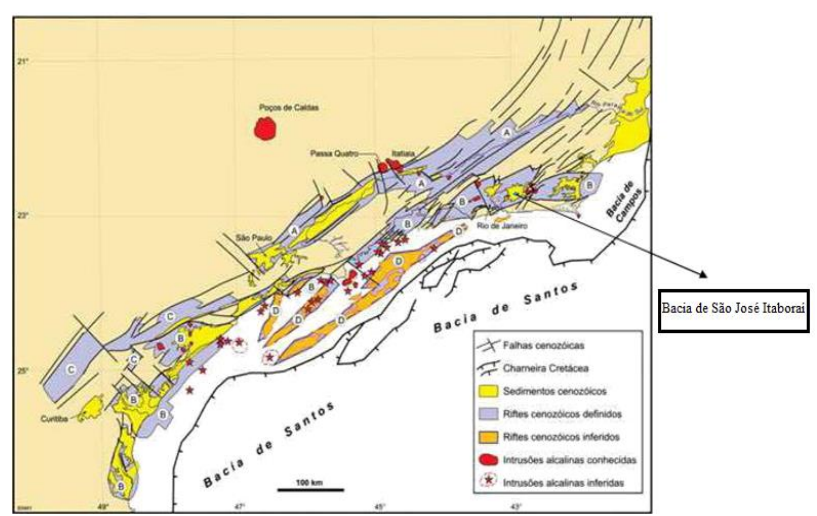

Figura 2 - Mapa de distribuição Sistema Rift Cenozoico do Sudeste do Brasil adaptado com a localização aproximada da Bacia de São José de Itaboraí em azul claro. (ZALAN \& OLIVEIRA, 2005).

O desnível entre a Serra do Mar e a Baixada de Itaboraí, pode atingir mais de $2000 \mathrm{~m}$. A origem desse relevo se deve a esforços tectônicos iniciados a cerca de 80 milhões de anos que provocaram um amplo soerguimento da borda do continente, desde o Paraná até o Espírito Santo (FERRARI, 2001). Com o aumento da elevação de um lado, houve rompimento e consequente rebaixamento dos blocos crustais adjacentes. A parte alta corresponde às Serras do Mar e da Mantiqueira e aos Maciços Litorâneos. Nas partes baixas, formaram pequenas bacias sedimentares, como a de São José de Itaboraí, cuja idade geológica é de aproximadamente 65 milhões de anos.

As serras do Mar e da Mantiqueira e os maciços litorâneos, são constituídos, em geral, por gnaisses, migmatitos e granitos paleo-neoproterozóicos a paleozóicos. Rochas calciossilicatadas e mármore ocorrem na forma de lentes localmente encaixadas no gnaisse. A dissolução destas lentes de mármore possibilitou a deposição dos carbonatos na bacia de São José de Itaboraí do Paleoceno (BERGQVIST, et al., 2008).

A Bacia, propriamente dita, foi preenchida por uma sucessão de depósitos, principalmente carbonáticos, que se sobrepõem aos calcários cristalinos, gnaisses, granitos e pegmatitos localizados na parte mais profunda (BRITO, 1989). A principal estrutura observada é a falha de São José, que delimita o sul da Bacia. É uma falha normal, bastante evidente em observações de campo. No plano dessa falha já foram observadas pequenas falhas reversas. Brito et. al (1972) admitem que a Bacia é limitada em sua borda sul por uma falha aproximadamente vertical e de sentido E-W, e cujo bloco formado pelo embasamento cristalino da borda sul foi elevado, deixando uma depressão que foi posteriormente preenchida por calcário. O mesmo autor também admite o preenchimento da Bacia por diferentes camadas de calcário com maior espessura ao longo da falha.

\section{Geologia Local}

A Bacia de Itaboraí, de idade paleogênica, é a menor e mais antiga Bacia incluída no contexto do Rift Continental do Sudeste do Brasil (RICCOMINI, 1989). Apresenta formato elíptico, com 1500 a 2000 metros no semieixo maior, e apenas 500 metros no menor. Como registrado a partir de numerosas sondagens feitas na época da exploração, sua espessura máxima atingia cerca de 100 metros (LEINZ, 1938; RODRIGUES -FRANCISCO \& CUNHA, 1978; BERGQVIST et al., 2005 apud ADLER, 2017). Um mapa geológico simplificado da Bacia está apresentado na Figura 3.

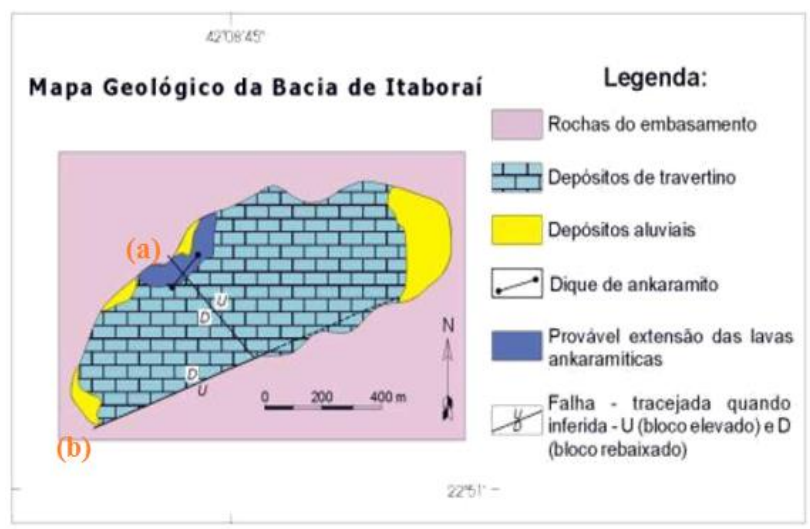

Figura 3 - Mapa geológico simplificado da Bacia de Itaboraí, indicado em (a) Falha de São José e (b) Falha Transversal. (modificado por RODRIGUES-FRANCISCO, 1975).

Medeiros \& Bergqvist (1999) reuniram as associações das fáceis da Bacia de Itaboraí em três sequencias estratigráficas, as quais designaram como S1, S2 e S3, que correspondem, em parte, aos três pacotes indicadas por Leinz. As sequências S1 e S2 foram definidas pelos autores como predominantemente carbonáticas, e a sequência S3, clástica.

A sequência S1 ocorre sobre o embasamento cristalino Pré-cambriano, e nela predomina uma intercalação de carbonatos de origem química e carbonatos com algum teor de clásticos, interdigitados, com uma grande quantidade e diversidade de fósseis de moluscos, restos de plantas e alguns répteis e mamíferos. Três litofácies principais foram reconhecidas nesta seqüência: travertino, calcário cinzento e calcário oolítico-pisolítico. A fácies de calcário travertino é de origem inorgânica; possui um arranjo bandado lembrando estruturas estromatolíticas, e apresenta uma variedade de cores. A fácies de calcário oolítico-pisolítico ocorre associada ao calcário travertino, sendo composta por grãos de $1,0 \mathrm{~mm}$ a 10,0 mm, geralmente elipsoidal, com núcleo constituído por grãos minerais e, muito raramente, por pequenos gastrópodes. A fácies de calcário cinzento é, na realidade, uma associação de fácies que grada lateralmente de calcirruditos, calcarenitos a calcários arenosos e argilosos. O acamamento é geralmente 
maciço, mas localmente ocorre gradação normal ou inversa. Esta associação de fácies é encontrada intercalada com o calcário travertino e formando o assoalho da bacia (Medeiros \& Bergqvist, 1999). A origem da sequência $\mathrm{S} 1$ estaria relacionada a fluxos hidrodinâmicos e gravitacionais dentro de um lago tectônico raso. Os carbonatos químicos foram predominantemente originados em fontes termais localizadas ao longo do bordo sul, tectônico e sismicamente ativo.

Após a deposição dos carbonatos da sequência $\mathrm{S} 1$, iniciou-se um processo de dissolução e abertura de fissuras formando a topografia cárstica da sequência intermediária S2. Os sedimentos de preenchimento das fissuras correspondem a uma única fácies caracterizada por margas e calcirrudito, transportadas para dentro destas fissuras por enxurradas e fluxos gravitacionais, com marcante conteúdo fossilífero, incluindo diferentes tipos de vertebrados, invertebrados e restos remanescentes de plantas.

A última sequência S3 é composta por depósitos clásticos terrígenos grossos, incluindo conglomerados com matriz arenosa a lamosa, a origem destes sedimentos corresponde a leques aluviais vindos de áreas marginais soerguidas.

A bacia de São José possuiu duas estruturas importantes, ocorrido devido ao falhamento direcional da falha de São José que tem um direcionamento SW-NE e outro falhamento reverso para a falha transversal no sentido NW-SE. Na borda oeste da bacia, foi perfurado em 2009 o poço 2-ITAB-1-RJ, atingindo $70 \mathrm{~m}$ de profundidade, com $75 \mathrm{~mm}$ de diâmetro e testemunhagem continua com estimativa de recuperação de $50 \%$. O testemunho do poço 2-ITAB-1-RJ até 40 metros de profundidade seguem na Figura 4. A profundidade até 3 metros registrou um material areno argiloso inconsolidado, cinza, onde a fração silico-argilosa apresenta coloração cinza. Entre 3 a 7 metros profundidade, possuí intercalações de níveis delgados de calcário travertino fitado, com laminação estromatolítica com vugs preenchidos por carbonatos e níveis de margas cinza escuras. De 7 a 14 metros, marga cinza média com fragmentos de travertino, calcário duro, diamectito com matriz de marga com intercalações de carbonato róseo, travertino fitado creme-róseo, com vugs preenchidos por calcita, intervalos brechado e níveis de marga. De 14 a 20 metros, calcário fitado brechado, vugs preenchidos por carbonatos, marga cinza com fragmentos de calcário, quartzo e feldspato, conglomerado (diamectito) com classes de carbonato róseo e quartzo, matriz arenoargilosa carbonática. De 20 a 30 metros, calcário conglomerático, duro, cimentado com clastos de calcário cristalino e matriz areno-argilosa, clastos de k-feldspato róseo conglomerado (diamectito) com grande clastos de feldspato, calcário travertino (fitado), róseo, com vugs alongado e vugs menores, calcário argiloso com marga. De 30 a 38 metros calcarenito argiloso, calcarenito conglomerático, maciço com matriz argilosa carbonática, conglomerado com matriz areno-argilosa, material arenoconglomerático, cinza-escuro com clastos de quartzo feldspato e por fim a biotita gnaisse.

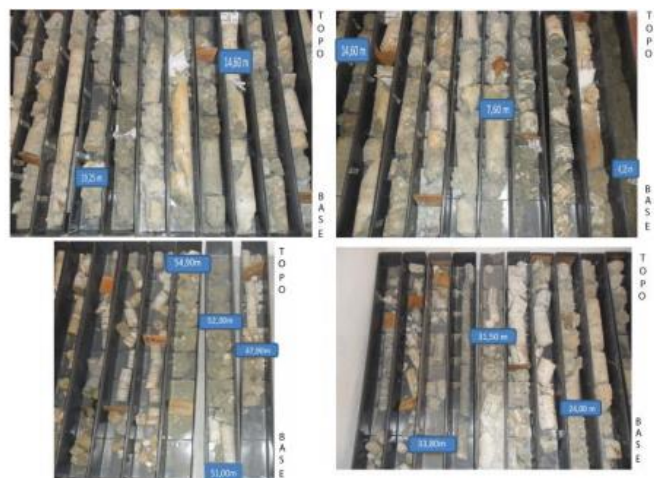

Figura 4 - Testemunhos retirados do poço 2-Itaborai-1-RJ (Oliveira, 2012).

\section{Aquisição de dados geofísicos}

O equipamento GPR utilizado foi modelo SIR System3000 fabricado pela Geophysical Survey Systems Incorporated, Inc (GSSI), possui duas antenas uma blindada e uma não blindada, de 200 e $35 \mathrm{MHz}$ (Multiple Low Frequency - MFL, suas dimensões variam de 120 a $600 \mathrm{~cm}$ podendo ser operadas a frequências de 15 a 80 $\mathrm{MHz}$ ) (Figura 5). O modo de aquisição utilizado foi de afastamento constante (common offset - COS).
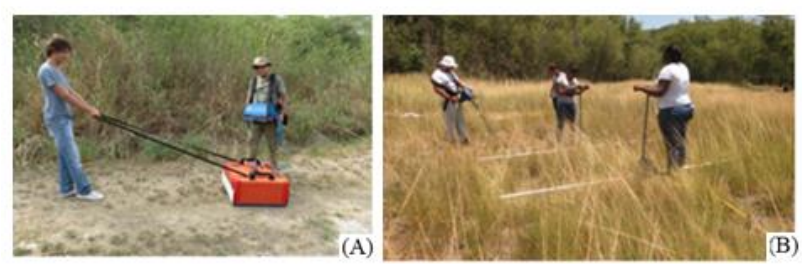

Figura 1 - (A) Antenas blindadas (modo monoestático). (B) Antenas não blindadas (modo biestático). Equipamento GPR.

Com a antena de $200 \mathrm{MHz}$ e $35 \mathrm{MHz}$ se investigou $7 \mathrm{~m}$ e $40 \mathrm{~m}$ de profundidade, respectivamente. O perfil de reflexão se constrói a partir da emissão de pulsos eletromagnéticos sucessíveis, a distância constante entre as antenas foi de $2 \mathrm{~m}$ até formar um perfil para atingir uma linha, reta, obtida pela movimentação do GPR. Assim foram gerados três perfis (linhas) (Figura 6).

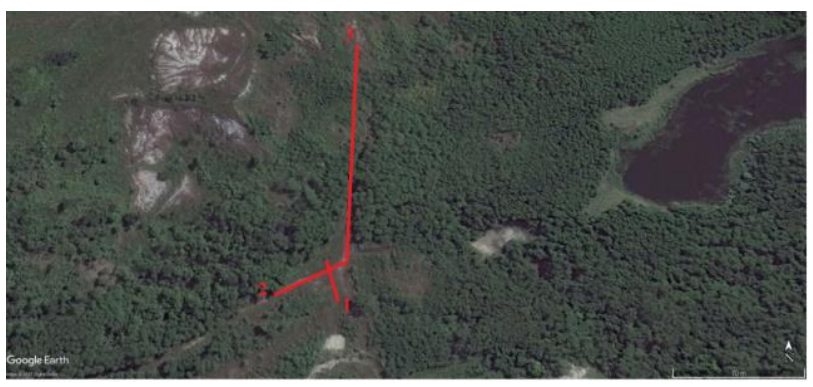

Figura 6 - Linhas de aquisição GPR, sinalizado com linhas em vermelho correspondem aos perfis de aquisição 1, 2 e 3 . Imagem do obtida do Google Earth ${ }^{\mathrm{TM}}$ (2017).

Para aquisição dos dados ERT foi utilizado o equipamento syscal kid switch 24 systems, um sistema compacto de medição de resistividade com medição IP \& SP, possui incorporado para 24 multi-eletrodos com espaçamentos de $5 \mathrm{~m}$. As aquisições dos dados foram 
feitas com o arranjo dipolo-dipolo, através de dois perfis (linhas) onde os eletrodos foram espalhados (Figura 7). $\mathrm{O}$ perfil ERT 01 e o perfil ERT 02 corresponderam as linhas 02 e linha 03 respectivamente do GPR.

Figura 7 - (A) Cabos dos eletrodos. (B) Perfil de aquisição. (C)

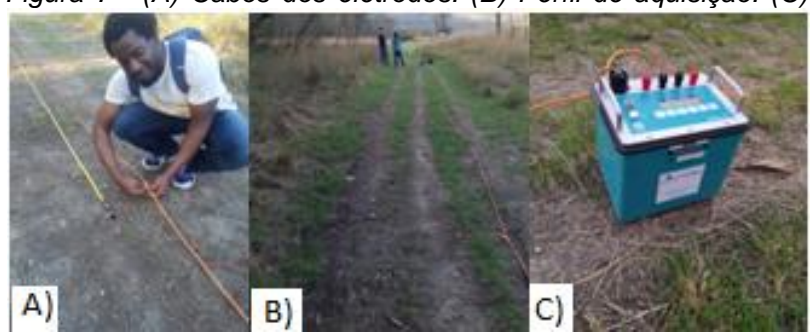

Equipamento ERT.

\section{Processamento e interpretação das linhas na área de estudo}

Os dados obtidos com as antenas de $35 \mathrm{MHz}$ e 200 $\mathrm{MHz}$, foram processados através do software ReflexW. Foram utilizados no processamento, os filtros static correction/muting, move starttime, 2D Filter bacground removal, 1D Filter subtract-mean (dewow), 1D Filter bandpass frenquecy e migração. Os valores utilizados em cada um dos filtros são diferentes e foram ajustados para melhor interpretação das seções radargramas.

Para a antena de $35 \mathrm{MHz}$ as figuras 8,9 e 10 correspondem consecutivamente as seções-radargramas das linhas 1,2 e 3. Para a figura 8, linha 1, entre 0 a $5 \mathrm{~m}$ de profundidade os refletores são ondulados de aspecto entrecruzados com geometria côncava para baixo e para cima (delimitado pela linha em vermelho - argila inconsolidada), de 5 a 15 metros de profundidade os refletores são cruzados (delimitado pela linha em laranja - pode vir a caracterizar a fronteira entre um material mais argiloso e o calcário travertino). Entre 15 a $30 \mathrm{~m}$ são observadas refletores contínuos e paralelos, às vezes irregulares (representação do calcário fitado). As hipérboles representam nódulos de marga ou calcário duro (nas seções radargramas as hipérboles em azul apresentam valores velocidades de aproximadamente 0,1 $\mathrm{m} / \mathrm{ns}$ correspondente às rochas em profundidade e para a hipérbole em verde essa corresponde à presença da onda área - torre de alta tensão acima do perfil). Para a Figura 9, linha 2 entre 0 a $5 \mathrm{~m}$ de profundidade os refletores são ondulados de aspecto entrecruzados com geometria bastante irregular (delimitado pela linha em vermelho), de 5 a 15 metros de profundidade os refletores são cruzados, com estrutura côncava para baixo (delimitado pela linha laranja). Entre 15 a 30 m são observadas refletores contínuos e paralelos, às vezes irregulares (representação do calcário fitado). Para a Figura 10, linha 3 , entre entre 0 a $5 \mathrm{~m}$ de profundidade os refletores são pouco contínuos ondulados e apresenta refletor com geometria côncava para baixo (delimitado pela linha em vermelho), de 5 a 15 metros de profundidade apresenta grande quantidade de refletores com concavidades mais fechadas (delimitado pela linha em laranja). Entre 15 a $30 \mathrm{~m}$ não se pode observar os refletores devido à presença de múltiplas.

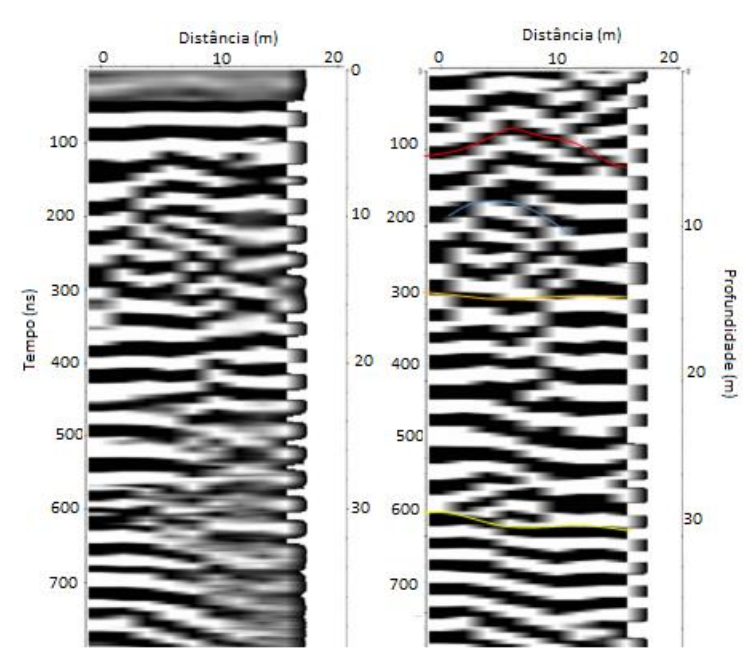

Figura 8 - Linha 1 (direção N45E), a esquerda o radargrama não processado e a direita o radargrama processado.

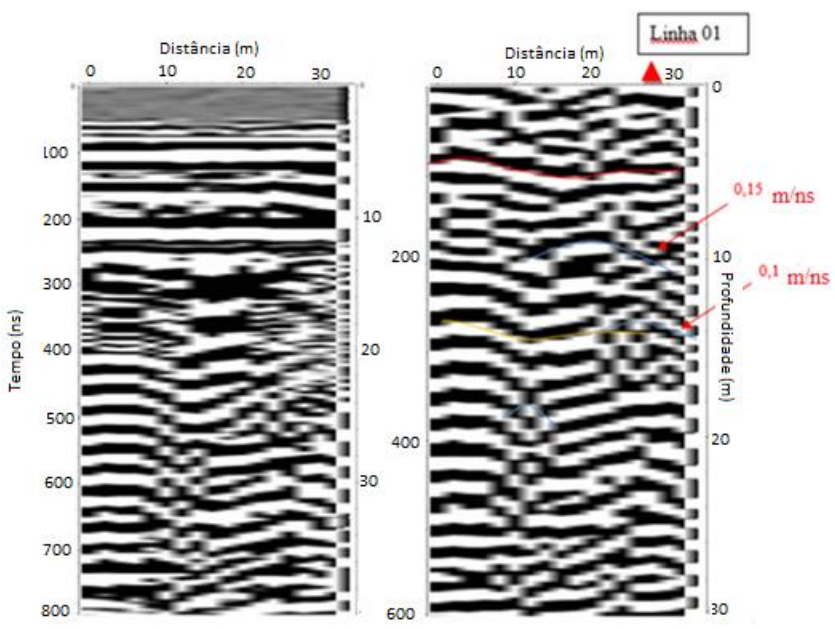

Figura 9 - Linha 2 (direção N20W), a esquerda o radargrama não processado e a direita o radargrama processado.

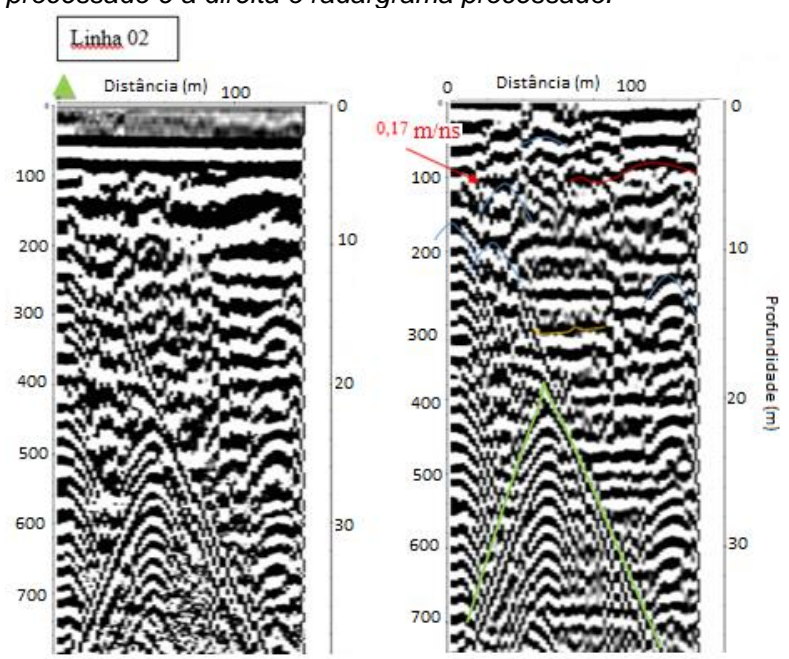

Figura 10 - Linha 3, A esquerda o radargrama não processado e a direita o radargrama processado. 
Para a antena de $200 \mathrm{MHz}$ as figuras 11, 12 e 13 correspondem consecutivamente as seções radargramas obtidas sobre as mesmas linhas 1,2 e 3 da frequência em $35 \mathrm{MHz}$. A existência de uma estrutura plana, observadas nas seções radragramas geradas pela antena de $200 \mathrm{MHz}$, sinalizada em vermelho a 3 metros de profundidade, delimita o limite entre as camadas. Entre 3 a 7 metros profundidade, segundo a descrição do poço 2-ITAB-1-RJ, possuí intercalações de níveis delgados de calcário travertino fitado, com laminação estromatolítica com vugs preenchidos por carbonatos e níveis de margas cinza escuras que podemos correlacionar na interpretação das seções radagramas gerados com a antena de $200 \mathrm{MHz}$, os níveis delgados de calcário travertino fitado, abaixo de 7 metros as seções radargramas existem uma má qualidade dos dados, que pode ser correlacionado a presença de marga.

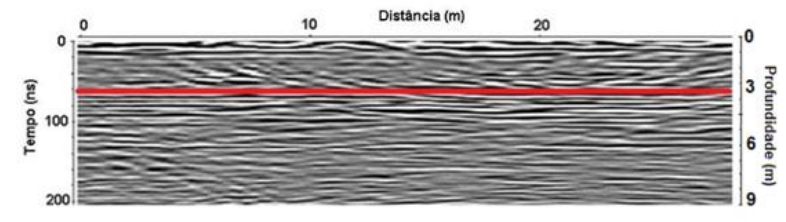

Figura 11 - Linha 1 com processamento e interpretada.

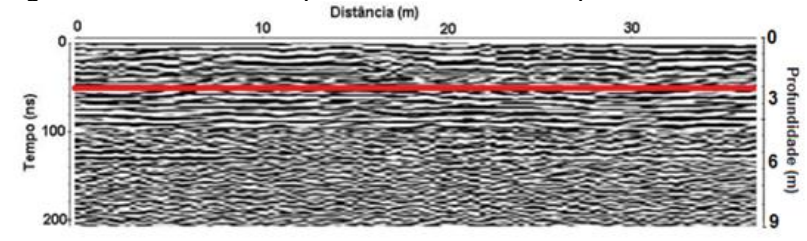

Figura 12 - linha 2 com processamento e interpretada.

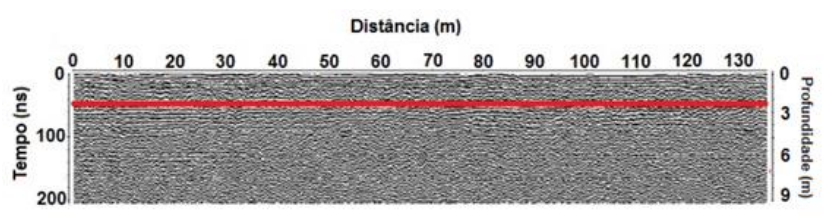

Figura 13 - Linha 3 com processamento e interpretada.

Para interpretação dos dados foi utilizado o programa RES2DINV, o qual usa rotina de inversão baseada na suavização do método dos mínimos quadrados. De acordo com os dados de campo, onde são também fornecidas informações sobre o arranjo de eletrodos utilizado, o programa simula a injeção de corrente e os potenciais nos eletrodos, sendo em seguida realizada a inversão dos dados de forma que as isolinhas de resistividade possam definir com maior precisão a posição e o formato das estruturas causadoras de anomalias. Na seção de resistividade de 0 a $7 \mathrm{~m}$ de profundidade nas seções de resistividade os valores altos de resistividade acima de 22 ohm.m podem ser associados concreções associadas aos carbonatos e abaixo desse valor a material de aterro (Figura 14), abaixo de $7 \mathrm{~m}$ apresenta-se uma característica mais homogênea, sendo correspondem a carbonato com presença de marga. Já na seção de resistividade 02 de 0 a 7 metros de profundidade os valores de resistividade estão abaixo de 22 ohm.m o qual mostra que essa seção representa uma parte mais baixa da borda da bacia preenchida por material argilo-arenoso com a presença de carbonatos ao lado direito da seção.

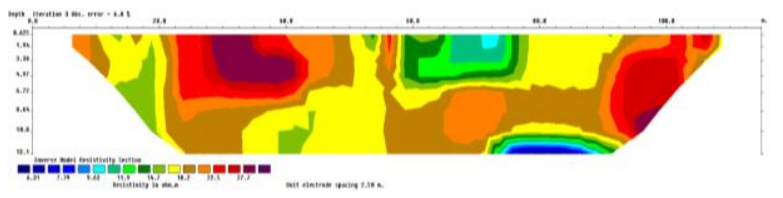

Figura 14 - Seção de resistividade da linha 01.

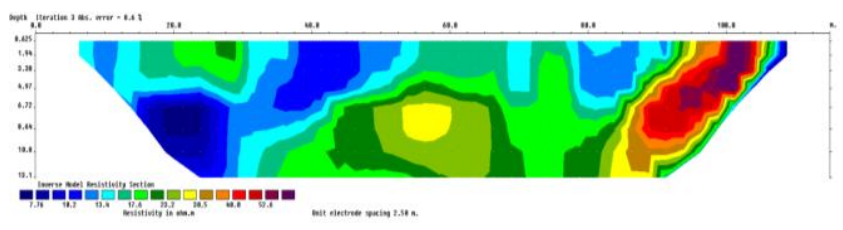

Figura 15 Seção de resistividade da linha 02.

\section{Conclusão}

Nas três seções radargramas interpretadas podem ser verificadas as correlações dos dados com descrição litológica do poço que está inserida na linha 01. Os dados utilizados em Miranda (2015) com antena de $200 \mathrm{MHz}$ apresentaram uma melhor resolução quando comparado com o uso das antenas de $35 \mathrm{MHz}$, com profundidade de $9 \mathrm{~m}$ e $40 \mathrm{~m}$ respectivamente. Na interpretação dos dados da antena de $200 \mathrm{MHz}$ pode ser verificado que esses foram prejudicados pela presença de marga no meio, sendo verificados a interface areia e carbonato a profundidade de $7 \mathrm{~m}$. Já para a frequência de $35 \mathrm{MHz}$, nem todas as interfaces do perfil estratigráfico foram detectadas pelas ondas eletromagnéticas, 0 que caracteriza que para o estudo de reservatórios com carbonatos algumas interfaces que variam com presença de carbonato-areia-argila verificada nas seções estratigráficas não podem ser diferenciadas por um método geofísico utilizado. As seções de resistividade apresentaram um resultado interessante juntamente com os dados de radar, os valores de baixa resistividade correspondente ao material inconsolidado (de aterro e exógeno), apresentaram mais características estruturais quando comparado as rochas carbonáticas.

Os resultados mostram que o uso do método geofísico de eletrorresistividade com o GPR vem a colaborar na identificação de tipos litológicos em subsuperfície para a elaboração do modelo geológico.

\section{Referências Bibliográficas}

ADLER, P. A. B. Calcretes e Travertinos da Bacia de Itaboraí, Estado do Rio de Janeiro 228 f. Dissertação (Mestrado em Geologia) - Instituto de Geociências da UFRJ, Rio de Janeiro, 2016.

BERGQVIST, L.P.; RODRIGUES, M.A.; MANSUR, K.; RODRIGUES-FRANCISCO, B.H.; PEREZ, R. \& BELTRÃO, M.C. 2008. Bacia de São José de Itaboraí, RJ: O berço dos mamíferos no Brasil. Artigo SIGEP 
BRITO, I.M., FRANKE, H.E. \& CAMPOS, D.A. 1972. Geologia e Petrografia da Bacia de São José de Itaboraí, Estado do Rio de Janeiro. (1972). Anais da Academia Brasileira de Ciências. Rio de Janeiro, 44(2): 225-233.

BRITO I. M. 1989. Geologia e paleontologia da Bacia Calcária de São José de Itaboraí, Estado do Rio de Janeiro. Brasil. Anuário d o Instituto de Geociências. UFRJ. P. 56-64.

DIAS, G. A. N. 2007. Modelagem e imageamento dos dados de GPR adquiridos em afloramentos visando o estudo de reservatório petrolífero. $196 \mathrm{f}$. Tese (Doutorado em Ciêcias em Geologia) - Instituto de Geociências da UFRJ, Rio de Janeiro.

LEINZ, V. 1938. Os calcáreos de São José de Niterói, estado do Rio. Mineração e Metalurgia, 3(15): 153-155.

MEDEIROS, R.Á. \& BERGQVIST, L.P. 1999 Paleocene of the São José de Itaboraí Basin, Rio de Janeiro, Brazil: Lithoestratigraphy and Bioestratigraphy. (Estudos Tecnológicos: Acta geológica leopondensia 1999) (XXII (48): 3-22.

MENESES, R. M. X. 2009. Trabalho de Conclusão de Curso: Levantamento por Eletrorresistividade na Bacia de São José de Itaboraí - Rio De Janeiro. Rio de Janeiro: Universidade Federal do Rio de Janeiro - RJ, 2009.

MIRANDA, R.A. \& DIAS. 2015. GPR e eletrorresistividade em carbonatos da Bacia de São José de Itaboraí, RJ. Artigo para $14^{\circ}$ simpósio de Geologia do Sudeste.

RICCOMINI, C. 1989. O Rift continental do sudeste do Brasil. 1989. 190f (Doutorado em Geologia Sedimentar) Instituto de Geociências, Universidade de São Paulo, São Paulo,1989.

RICCOMINI C., Sant'Anna L.G., Ferrari A. L. 2004. Evolução geológica do Rift Continental do Sudeste do Brasil. In: Mantesso-Neto V., Bartorelli A., Dal Ré Carneiro C., Brito Neves B.B. (eds.). Geologia do Continente Sul-Americano: Evolução da Obra de Fernando Flávio Marques de Almeida. São Paulo, Editora Beca, p. 383-405.

RODRIGUES-FRANCISCO, B. H. \& SOUZA CUNHA, F. L. 1978. Geologia e Estratigrafia da Bacia de São José, Município de Itaboraí, RJ. Anais da Academia Brásil de Ciências, 50 (3).

SEIXAS E. GOMES. 2018. O uso do Radar de Penetração do Solo (GPR) no Parque Paleontológico de São José de Itaboraí, Itaboraí - RJ /. Rio de Janeiro: UFRJ/IGEO.

ZALÁN, P. V. \& OLIVEIRA, J. A. B. de. 2005. Origem e Evolução Estrutural do Sistema de Riftes Cenozóicos do Sudeste do Brasil. (2005). Boletim de Geociências da Petrobras, Rio de Janeiro, vol. 13, no 2, p. 269-300. 